\section{IMPLANT PRESERVES MARGINAL BONE}

NobelActive from Nobel Biocare is minimally invasive to ensure accurate placement and the implant has the ability to change direction during surgery, offering full flexibility, optimal placement and complete confidence to the professional.

Designed to gently compress the bone like a corkscrew, the narrow neck of NobelActive will preserve marginal bone and promote long-lasting soft tissue sta- bility. It also offers high initial stability, even in compromised bone situations, a bone condensing property, redirecting capability for optimal placement, built-in platform shifting and dualfunction prosthetic connection.

Reader response number 54

\section{PROTECT YOUR PATIENTS IMPLANTS'}

Providers of cost effective practice branded dental payment plans, DPAS, are now offering existing customers a Dental Implant Accident Protection Policy, underwritten by ACE European Group and designed to help protect your patients against unexpected accidents that cause damage to one or more of their implants.

With success rates of over 95\%, dental implants are undoubtedly an attractive treatment option but in the small number of cases where damage occurs, implant insurance can be of great value.
By committing to a premium of only £25.20 per year, regardless of the number of dental implants placed, patients who need to claim can receive up to $£ 2,500$ per implant towards the cost of repair or replacement.

Together with additional benefits that compensate for the inconvenience of a hospital stay or travel costs when patients return to their chosen implant dentist following an accident, DPAS's implant insurance offers patients peace of mind when committing to this high value treatment.

Reader response number 55

\title{
VIRTUAL TREATMENT PLANNING SOLUTION
}

BioHorizon's new Virtual Implant Placement (VIP) treatment planning provides a user friendly, virtual treatment planning solution that reduces clinical challenges and enhances postoperative outcomes from both a clinical and aesthetic perspective.

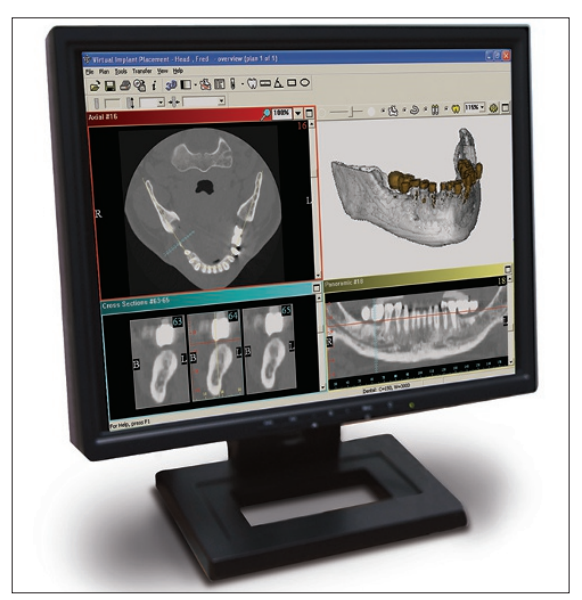

VIP provides interactive 2D and 3D treatment planning which enhances case predictability and confidence and ultimately improves the communication between dentist and patient. Other key advantages include a user-friendly interface and easy to use tools as well as the unique ability to self process digital images, saving both time and money.

BioHorizons have also introduced MemLok, a new resorbable collagen membrane. Mem-Lok is a type I collagen matrix that hinders epithelium down growth and prevents connective tissue cell migration. Derived from bovine achilles tendon, this permeable membrane offers high mechanical strength. Mem-Lok has an optimised balance of flexibility and rigidity and a macromolecular pore size that allows nutrient transfer into the wound site.

Reader response number 56

\section{ADVANCED CAD/CAM TECHNOLOGY FOR ABUTMENTS}

The Swedish medical device company Astra Tech AB, a subsidiary of AstraZeneca, is introducing the Atlantis solution for all major implant systems. Atlantis increases productivity and cost efficiency in the dental laboratory as the lab can deliver high quality, customised abutments with less time and effort and can also be used for routine cases to ensure a perfect fit.

With the advanced patented Atlantis VAD (Virtual Abutment Design) software, the abutments are uniquely designed from the final tooth shape. The need for chairside modification is eliminated as each abutment is made to be anatomically correct and specific to the space it will fit.

The Atlantis solution works with titanium, gold shaded titanium and zirconia materials and Astra Tech have also started cooperating with 3M ESPE for digital scanning with the Lava Scan ST System. With this new scanning option, laboratories using the Lava Scan ST System can place orders without having to send a model to Astra Tech.

Reader response number 57

\section{STUDENT CLINICIAN PRO- GRAMME AWARDS ANNOUNCED}

The Dentsply Student Clinician programme, which is supported by the BDA, is designed to help students showcase innovative, original clinical and research work at undergraduate level.

The Student Clinician Awards (to be held on Friday 5 February 2010 at the Balmoral Hotel, Edinburgh) will feature fourteen finalists from teaching schools around the country presenting their research material for adjudication from three experts, Professor John Drummond, Professor Nairn Wilson and Professor Robert McConnell.

Dentsply will also be hosting a reception and dinner.

Reader response number 58 